\title{
FEMINISMOS NÃO HEGEMÔNICOS CONTEMPORÂNEOS: LUTAS COTIDIANAS EM DEFESA DE TERRITÓRIOS CORPO-TERRA
}

\author{
CONTEMPORARY NON-HEGEMONIC FEMINISMS: \\ DALLY STRUGGLES IN DEFENSE OF THE BODY-EARTH TERRITORIES
}

\section{RESUMO}

O objetivo deste texto é realizar uma análise sobre a defesa de territórios por mulheres do Brasil Meridional, a partir de epistemologias que germinam através do engajamento e das trajetórias de vida dessas mulheres, tendo como pano de fundo o meio rural e a agricultura: assentadas da reforma agrária e quilombolas. Serão abordados saberes construídos, moldados e salvaguardados por mulheres, tais como a experiência de farmacinhas com plantas medicinais, presentes em alguns assentamentos do MST (Movimento dos Trabalhadores Rurais sem Terra), ou a atuação de mulheres quilombolas, reunindo experiências de campo vividas pelas pesquisadoras no extremo sul do estado do Rio Grande do Sul, Brasil. Pretendemos realizar conexões desses relatos com as críticas feitas por feminismos comunitários, negros e pós-coloniais que problematizam processos geopolíticos e históricos da colonização ocidental e relações diaspóricas, formando outros fluxos diante de configurações sociais e políticas em alguma medida compartilhadas.

Palavras-chave: Plantas medicinais. Movimento dos Trabalhadores Rurais sem Terra. Gênero. Quilombos.

\begin{abstract}
The objective of this text is to perform an analysis on the defense of territories by women from Southern Brazil, from epistemologies that germinate through the engagement and life trajectories of these women, having as background the rural environment and agriculture: settled of the reform agrarian and quilombolas. Will be approached knowledge built, molded and safeguarded by women, such as the experience of medicinal plants with herbs, present in some settlements of the Landless Rural Workers Movement, or the work of quilombola women, gathering field experiences lived by the researchers in the extreme south of the state of Rio Grande do Sul, Brazil. We intend to make connections between these reports and the criticisms made by communitarian, black and postcolonial feminisms that
\end{abstract}

Patrícia dos S. PINHEIRO

PPGA/UFPB. Email: patriciasantspinheiro@gmail.com

Maysa L. SILVA

Prefeitura de São Bernardo do Campo (Técnica de Proteção Social na Abordagem Social). Email: maysaluana93@gmail.com

Marcela P. RODRÍGUEZ

Universidad Catolica del Norte. Chile. Email: pazlaley@hotmail.com 
problematize the geopolitical and historical processes of Western colonization and diasporic relationships, forming other flows in the face of social and political configurations to some extent shared.

Keywords: Medicinal plants. Movement of Landless Rural Workers. Genre. Quilombos.

\section{Introdução}

A insistente predominância de análises oriundas ou calcadas na produção das ciências sociais europeias e norte-americanas tem sido problematizada ao longo das últimas décadas com debates sobre subalternidade, estudos culturais, feministas, pós-coloniais e pela produção de teorias oriundas do Sul, entre outras perspectivas, instigando pesquisadores a repensar os sistemas de poder e saber com as quais nossos trabalhos acadêmicos têm sido construídos, sem, no entanto, nos levar a um caminho pré-determinado. Essas diferentes perspectivas, dentro de um horizonte de sentidos bastante heterogêneo e sempre incompleto, problematizam o totalitarismo explicativo do pensamento hegemônico sobre diversos objetos de análise e expandem as possibilidades de lugares de enunciação subalternos (Castro-Gómez, 2005).

Neste texto, provocadas pela premência de contínuas pesquisas que possam relacionar saberes não hegemônicos e com a clareza dos limites de tal tarefa, nos propomos a refletir sobre como fenômenos sociais de contextos tidos frequentemente como "periféricos", com experiências da vida social múltiplas, realizam-se fora de uma expectativa totalizante de organização do mundo social ocidental e têm estimulado uma renovação dos paradigmas teóricos consolidados e de categorias analíticas das ciências sociais calcadas no conhecimento teórico colonial. Com o olhar para o local,

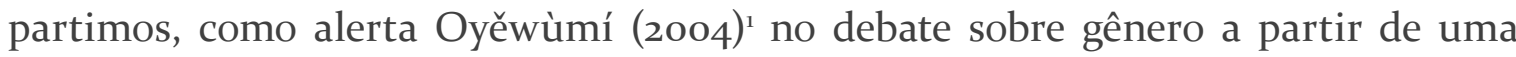
perspectiva africana, da ideia de que não é possível ver as relações de gênero e suas expressões de subordinação enquanto homogêneas ou universais, mas sim como construções socioculturais vista em suas nuances, que torna necessária a pergunta: qual a concepção de diferença em questão?

Ao se debruçar sobre essas nuances, o objetivo é realizar uma análise sobre a relação que as mulheres estabelecem com seus territórios, pensando epistemologias que germinam através do engajamento e de suas trajetórias de vida, tendo como pano de fundo o meio rural e a agricultura para assentadas da reforma agrária e

1 Oyěwùmí (2004) tece sua crítica sobre a teoria feminista ocidental afirmando que há uma centralidade na família nuclear ocidental nessa perspectiva, a partir de onde teriam se conformado os seus principais conceitos e fundamentos, deixando de lado assim outras formas de família não generificada, como o caso por ela estudado, na Nigéria. 
quilombolas do Brasil Meridional². Procuraremos abordar saberes construídos, moldados e salvaguardados majoritariamente por mulheres, reunindo aqui experiências de campo vividas pelas pesquisadoras no interior dos municípios de Canguçu e São Lourenço do Sul, no estado do Rio Grande do Sul.

Ressaltamos, de antemão, que não há uma pretensa homogeneidade entre esses grupos, que podem apresentar antagonismos e diferenças epistemológicas que transparecem em seus engajamentos políticos e em suas lutas cotidianas. O que as aproxima, por outra perspectiva, é que fazem parte de grupos sociais que passaram por diversas tentativas de serem "desenvolvidos" ou de atingirem uma ideia de "modernidade", mesmo que sempre incompleta e que tenda a reforçar as divisões sociais e estruturas de poder presentes, incluindo as hierarquizações de gênero. Resistências? De algum modo sim, mas apesar das ingerências externas que em certos momentos parecem sobrepujar qualquer ação e restringir as existências a reações ao que é externo - nestes casos bastante calcado no saber científico, por um lado, da medicina, e por outro, da agricultura chamada de convencional -, é preciso enfatizar estes grupos sociais não se conformam somente como o polo oposto ao que é "desenvolvido", como se fosse uma simples resposta reativa (mesmo que de negação), ou ainda a uma periferia ao redor de um centro.

Assim, a proposta aqui é relacionar os estudos de contextos múltiplos com trabalhos de campos realizados ao longo dos últimos anos no Brasil Meridional e, deste modo, realizar conexões destes relatos vinculados à defesa de territórios territórios-corpo e territórios-terra - com as críticas feitas por feminismos que se propõem a examinar processos sociais e históricos da colonização ocidental, relações diaspóricas, com a possibilidade de aproximação entre configurações sociais e políticas não hegemônicas. Iniciaremos com a descrição da farmacinha caseira conduzida pelas mulheres do Assentamento 12 de Julho, Canguçu, RS, a partir de pesquisa de Rodriguez (2017) e, posteriormente, saberes relacionados à produção e consumo de alimentos em comunidades quilombolas, em especial no Rincão das Almas, São Lourenço do Sul, RS, a partir de pesquisas de Pinheiro (2015) e Pinheiro e Rodrigues (2015).

Pensando nas expressões dos processos acima mencionados, em vários níveis e formas e relacionados entre si, buscaremos abordar autoras e autores vinculados ao debate sobre feminismos que nos mostram a impossibilidade da universalização do quadro ideológico do poder presentes no paradigma ocidental das relações de gênero, observando-as conectadas com outras formas de opressão e desigualdade presentes no mundo contemporâneo.

2 Chamamos a atenção para a necessidade de não enclausuramento em categorias analíticas que seguem sendo referência ocidental, ou, como aponta Rosa (2014: 48), "[...] categorias que o colonizadorcapitalista-globalizado criou para acomodá-los em uma ordem hierárquica de formas de conhecimento”, como indígenas, camponeses, ou mesmo quilombolas, sendo esta última atualmente uma categoria normativa que passou por uma série de ressignificações que podem englobar uma diversidade de existências que de algum modo se relacionaram com o período escravista no Brasil. Mas também não é possível ignorá-las como nomeações as quais grupos sociais investem significados atualmente e que se tornaram politicamente relevantes. 


\section{A Farmacinha Caseira}

As mulheres têm sido um pilar fundamental, tanto em espaços públicos quanto privados, em negociações, eventos, formulações e reformulações de saberes, o que vai em direta proporção a colaborar com a biodiversidade e a autonomia. E, desde tempos remotos, grupos comunitários - e sobretudo as mulheres - têm utilizado plantas nativas para realizar curas e proporcionar a proteção física e espiritual. Foram ainda parteiras e as primeiras herboristas, com seus cultivos de plantas medicinais (Federici, 2010; Preciado, 2008), cujos usos se transmitiam por aprendizagem, ajuda mútua e cuidado (Moll, 2010).

A chamada medicina tradicional, com sistemas terapêuticos fundamentados em culturas locais e/ou ancestrais para a manutenção da saúde, formou parte de nossa herança contemporânea. Tratam-se de saberes, conhecimentos técnicos e práticas que podem ser reconhecidos como patrimônio e que frequentemente são protagonizados por mulheres (Marques, 2008), os quais as conectam com a comunidade em seu conjunto. Diante disso, com base na pesquisa desenvolvida por Rodríguez (2017), apresentaremos brevemente o trabalho realizado pelas mulheres do Assentamento 12 de julho, no interior de Canguçu, que partilham um saber-fazer tradicional em sororidade 3 , por meio de receitas e cuidados. Esse saber-fazer é passado oralmente de geração em geração, encadeando uma femealogia ${ }^{4}$, que, nesse caso, concretiza-se em um lugar: uma farmácia caseira.

O Assentamento, um dos 16 presentes no município de Canguçu, localiza-se no quinto distrito, chamado de Cordilheira, a 54 quilômetros da sede 5 . Situado junto à Serra dos Tapes e Serra do Herval, o Assentamento 12 de julho foi o primeiro do Movimento dos Trabalhadores Sem Terra (MST) em Canguçu. Em uma área de 815 hectares descontínuos, que anteriormente compunham uma fazenda improdutiva, o assentamento se formou com 26 famílias (atualmente são 21) oriundas de áreas rurais do norte do estado do RS (cerca de 500 quilômetros de distância), onde estiveram acampadas, debaixo da lona ${ }^{6}$, na antiga fazenda Annoni, por até sete anos. O nome do assentamento justamente faz referência à data da chegada das famílias em Canguçu, no inverno de 1989, quando o local não possuía qualquer estrutura, como casas, saneamento, estradas e, por ser o primeiro assentamento do município, também contava com a desconfiança dos moradores do entorno, colonos de descendência alemã (Rodríguez, 2017).

Os relatos da alimentação escassa do período de acampamento e da chegada em Canguçu são recorrentes, associados ao necessário aproveitamento máximo da

\footnotetext{
3 Do latim sor, cujo significado é irmã, entendido como uma relação de amizade entre mulheres para atingir um objetivo em comum.

4 Conceito que utiliza o feminismo comunitário para se referir a uma genealogia de mulheres.

5 Canguçu fica no sudeste do RS e dista 61 quilômetros do município de Pelotas e 274 km de Porto Alegre, capital do estado. Possui uma população de 54.102 habitantes, majoritariamente rural, dos quais aproximadamente 2 mil habitantes são assentados da reforma agrária.

6 Com referência aos barracos temporários feitos de lona preta nos acampamentos.
} 
produção própria, como conta Ivette7, em entrevista realizada em 2016: "Agora as mulheres falamos e refletimos que soubemos alimentar os filhos, porque antes na época da Annoni, a gente tinha muito pouco [...] A gente valoriza a terra, valoriza o que a gente tem, porque soubemos alimentar nossas famílias bem com tão pouco" (Rodríguez, 2017: 55). Atualmente a produção se volta para policultivos associados à criação de animais em escala familiar, além da produção de queijo, leite e mel, doces de frutas locais, entre outros, utilizados para autoconsumo e também comercializados nas redondezas, em escolas, restaurantes e feiras, individualmente ou em cooperativas. No assentamento há uma preocupação em reduzir os gastos de produção e insumo externos (como agrotóxicos), a produção de alimentos saudáveis, manter práticas de trabalho justo e estimular o consumo sustentável (Rodríguez, 2017).

Assim como foi relevante sua participação na construção de uma soberania alimentar junto ao movimento de luta pela terra, as mulheres do assentamento também foram protagonistas nas ações políticas, marchas e outras mobilizações públicas, como nos casos de tentativas de desalojamentos no acampamento, como relata outra assentada, Lucimar: "É que nós temos uma larga caminhada, me lembro de uma vez que chegaram os militares e as mulheres foram à linha de frente com flores, me lembro que uma delas pôs uma flor na arma de um deles. Nós impedimos que eles entrassem e realizassem um massacre" (Rodríguez, 2017: 56).

Assim, entre os afazeres domésticos, a produção para o autoconsumo e para a comercialização, as mobilizações políticas e de organização comunitária do assentamento, a fabricação de medicamentos a partir de plantas também se constitui como importante tarefa para as mulheres do Assentamento 12 de julho e do MST. O movimento possui um setor nacional de saúde que fomentou a organização de farmacinhas em todos os assentamentos, com objetivo de estimular a autonomia também em relação à cura de enfermidades diversas ${ }^{8}$.

A farmacinha caseira é um espaço onde as mulheres, comadres, reúnemse para manusear as plantas medicinais colhidas na volta das casas ou no mato e transformá-las em remédios. Além da presença constante de jovens e crianças, está constituída por cerca de dez mulheres dentre 40 e 75 anos: Iselde Paris da Rosa, Lucimar Salete, Geny Salete, Iolanda Fortunata, Catarina Francisca da Rosa, Rosicler Padilha, Ivanir Risso, Neusa Polita, Lourdes Volpi, Lenir Filvoch. Com um profundo conhecimento adquirido sobre princípios ativos, toxidade, formas de elaboração e usos indicados, essas mulheres manipulam diversos remédios, utilizando os frutos, flores, folhas, raízes e talos para preparar as infusões, decocções, xaropes, tinturas e elixires e essências. Fazem pomadas, azeites vegetais e sabões antissépticos, partilhando e aprimorando os conhecimentos entre todas, combatendo a ideia de propriedade sobre o saber.

7 As entrevistas realizadas por Rodríguez no Assentamento 12 de julho ocorreram no ano de 2016.

8 Para o relato de outra trajetória vinculada ao trabalho com plantas medicinais entre assentados, ver De Carli (2013). 
Há cerca de 10 anos contam com um pequeno espaço, mas antes disso já realizavam cursos (promovidos pelo movimento e também pelo poder público) e produziam em casa os remédios, com colaborações coletivas para os ingredientes e utensílios, como vidros e álcool. Os remédios são trocados ou vendidos por um valor espontâneo, usado para dar continuidade à produção. Atrás do espaço da farmacinha também há uma horta medicinal comunitária, com mais de 30 tipos de plantas de uso terapêutico, além de uma horta onde as plantas estão dispostas de acordo com a parte do corpo a ser tratada e o horário mais adequado para seu consumo (chamada de "relógio do corpo humano").

Além do fortalecimento do corpo, também a relação entre o grupo é enfatizada por uma das participantes, Lourdes: "é importante para nós a farmacinha porque estão nossos remédios. Mas se não tem ninguém que pegue os remédios, que entre e tome um chimarrão, se não tem ninguém para conversar, então não serve. Porque a importância maior é estar entre nós reunidas" (Rodríguez, 2017: 97). Em uma relação imbricada permeada pelas plantas medicinais e pela farmacinha, cria-se e se fortalece um sentido de pertencimento ao grupo, em que se compartilha uma existência mais igualitária, "entre mulheres" (Rich, 1985).

Pensando algumas dessas expressões, Lorena Cabnal (2010) apresenta o feminismo comunitário como um processo de construção epistêmica que possa influir em questões sobre o território histórico, o corpo e relação com a terra ${ }^{9}$. A defesa do nuestro territorio cuerpo - tierra e a aproximação dos princípios políticos da proposta de feminismo comunitário implica na recuperação de seus territórios corpo como um ato político emancipatório, dada a importância em recuperar o corpo no embate histórico estrutural que se volta contra ele e sua subjetividade. Sem separar o corpo da terra (mas sem necessariamente limitar a uma imagem somente de doação, frequentemente associada à Mãe terra), fala-se em território-corpo e território-terra justamente por serem elementares em sua junção. Um fortalece ao outro em sua busca por autonomia (Cabnal, 2010).

O importante aqui é destacar que o manejo com a natureza através do que foi apresentado sobre a farmacinha das mulheres tem relação com a ideia proposta com Lorena Cabnal acerca dessa tríade território-corpo-terra. Por isso a defesa do corpo/terra não está separada da defesa do território, pois é nele que se constituem as relações e, consequentemente, defender o território é defender modos de vida singulares e a violência contra os recursos naturais é também uma forma de violência contra as mulheres.

9 Cabnal analisa os movimentos de mulheres indígenas de Santa Maria, xinkas da Guatemala, problematizando um cruzamento entre relações patriarcais tanto ocidentais quanto "originárias ancestrais" - legitimado por práticas espirituais das elites originárias, considerando que mesmo antes da colonização já havia uma heteronormatividade cosmogônica -, ambas constituídas sobre o corpo sexuado das mulheres, que gera um entronque patriarcal. Em sua forma contemporânea, Cabnal critica certos discursos de Buen vivir latinoamericano, um paradigma ancestral que fala que a natureza é generosa para contribuir com o bem comum que, mesmo sendo bastante progressista ao apontar as mazelas do colonialismo, acaba por não questionar formas ancestrais de sexismo e machismo. Para a autora, o buen vivir não será suficiente para uma boa vida em integridade, se continuar reforçando relações patriarcais. 


\section{Produção e alimentação na comunidade quilombola Rincão das Almas}

Com suas peculiaridades, a defesa pelos territórios entre camponesas e quilombolas aproxima aspectos práticos e simbólicos de saberes populares, agricultura e alimentação. Apesar da expressividade que grupos quilombolas têm atualmente em todas as regiões do Brasil, incluindo o Rio Grande do Sul, e seu reconhecimento estatal através de diferentes ações e políticas públicas, ainda permanecem situações de desvalorização diante das diferentes expressões do patrimônio cultural quilombola. Esses saberes foram construídos com criatividade diante de um passado ligado às mazelas do escravismo e de um presente em que os efeitos de uma história de privações, de desestruturação e de segregação racial ainda são sentidos e se refletem na falta de acesso a direitos básicos.

Por outro lado, essas delimitações fortaleceram vínculos de ajuda mútua que estão presentes nos territórios coletivos e mesmo com essas dificuldades, um dos inúmeros elementos que compõem esse rico patrimônio é o cultivo e consumo de alimentos, que se expressam em saberes transmitidos e reafirmados coletivamente de geração em geração nos quais as mulheres assumem uma posição relevante de guardiania. É a partir destes olhares que se intersecciona gênero e a questão racial em outro território a ser mencionado, o Rincão das Almas, comunidade negra localizada em São Lourenço do Sul, município vizinho de Canguçu.

Em seus 50 hectares, atualmente residem mais de 100 famílias nesta comunidade. O Rincão, anteriormente conhecido como Rincão dos Negros ou dos Forros, está a 25 quilômetros da sede de São Lourenço, em uma região que teve sua economia em grande parte voltada à cadeia produtiva do gado e, mais recentemente, do arroz e da soja, todos em larga escala. A primeira se ligava com as antigas charqueadas no município de Pelotas nos séculos XVIII e XIX ${ }^{10}$. Já as granjas de arroz, mesmo no pós-abolição, abrigaram a população negra dessa região em condições muito precárias de trabalho (Pinheiro, 2015). Assim como a rizicultura, a sojicultora é baseada em técnicas "modernas" de agricultura, com intenso uso de insumos e maquinário (como grandes aspersores e mesmo aviões para a aplicação de agrotóxicos), o que resulta na contaminação dos cursos d'água de toda a região.

A localização da comunidade é próxima de outros agrupamentos negros e, apesar de uma configuração fechada do espaço agrário regional - por um lado latifúndios em áreas mais planas, por outro por colônias de imigrantes teuto que foram incorporadas a partir de 1858 em áreas mais íngremes - dezenas de comunidades quilombolas se estabeleceram em todo o extremo sul e após a abolição muitos conseguiram se manter em seus territórios. Atualmente, há nessa região

10 Trata-se de uma forma de conservação da carne realizada industrialmente em charqueadas, com o dessecamento pela salga e exposição ao sol. As charqueadas eram estabelecimentos industriais que chegaram a ter mais de dois mil cativos em áreas muito próximas umas das outras, em um período em que a escravidão era disseminada em diversos setores da sociedade gaúcha. 
(que tem como polo o município de Pelotas) ao menos 43 comunidades, das quais a maioria já recebeu o certificado de autorreconhecimento como comunidade remanescente de quilombo da Fundação Cultural Palmares ${ }^{11}$, incluindo o Rincão das Almas. No município mencionado anteriormente, Canguçu, atualmente há mais de 15 comunidades.

O Rincão das Almas, em área mais plana, formou-se a partir de uma doação de terras por uma estancieira à família de cativos de sobrenome Pereira, ainda no século XIX, registrada em um mapa que foi guardado na comunidade até meados do século XX. Essa doação, porém, não resultou em títulos legais da terra, documentos inacessíveis a muitos por seus custos. Ao longo do tempo, parte desse território herdado foi expropriado por uma família já detentora de uma grande propriedade vizinha (no período de construção da rodovia BR 116, na década de 1960) e o mapa foi extraviado no processo de busca por regularização das terras pela comunidade.

O Rincão é um local de grande fixação de famílias negras, apesar da forte estigmatização pela qual esse território passou, a partir de marcas como o trabalho, os modos de vida e a alimentação. Um local que muitas famílias comandadas por mulheres tinham como refúgio, mostrando a importância da organização familiar a partir da figura materna. Conforme o diálogo entre seu Guilherme Rodrigues de Quevedo e Ieda Mourão, ambos moradores do Rincão, as dificuldades com a alimentação eram sentidas:

Guilherme: Aqui permanecia muita mulher sozinha, [...] com os filhos.

Ieda: A minha vó foi uma.

G: [...]. Então ela buscava comida na prefeitura, na prefeitura velha. De a pé, criatura, nas costas. Então ela pedia para minha mãe para eu ir junto. [...] De a pé, para buscar bóia para os filhos dela. Ieda, ela não está mais viva, a coitada, mas em meio dia nós ia em São Lourenço e voltava. O açúcar, era o açúcar rapadura, eu trazia o açúcar, o saco do açúcar, melava as costas [risos]. (Seu Guilherme, Ieda, 23/11/2013).

A importância das famílias organizadas a partir da figura materna é expressiva na comunidade e também a troca de terras familiares por cevadura, ou seja, por comida ou bens de consumo, ou ainda por pequenos valores em dinheiro, mas que recorrentemente se dava em condições de troca injustas. Assim, as dificuldades para o plantio iniciam-se com a falta de terra e meios de produção, pois aqueles que não migraram para os centros urbanos ficaram em seus diminutos territórios, alvo de

$11 \mathrm{O}$ processo de reconhecimento estatal das comunidades negras rurais teve início formal a partir da Constituição Federal, de 1988, e em especial do Artigo 68 do Ato das Disposições Constitucionais Transitórias (ADCT), porém com um processo administrativo bastante instável. Ver Leite (200o). 
expropriação ao longo do tempo. As famílias permaneceram em pequenos espaços, em geral impróprios à agricultura, mas que comportavam pequenas lavouras de subsistência de variedades de milho, feijão, batata, mandioca. Antes da construção da rodovia BR 116, a produção, sem agroquímicos e com poucos equipamentos (enxadas, foices), era associada à criação de animais em pequena escala, sendo que no Rincão as características físicas favoreceram a criação de gado, que era mantido solto. Após a instalação da estrada, tornou-se obrigatório o cercamento das propriedades, alterando a forma da comunidade se relacionar com o seu espaço (Pinheiro, 2015).

A produção agropecuária tornou-se muito limitada (mesmo aquela voltada para a subsistência), aumentando o número de pessoas que foram atuar como diaristas em lavouras e granjas de arroz, como peão na criação de gado ou ainda plantar de sócio ou meeiro, em que se cultivava na propriedade de outra pessoa, pagando os insumos (adubos, sementes) e deixando parte da produção para o proprietário, atividades que têm em comum o regime de trabalho precarizado. Dentre as possibilidades de trabalho atuais, além dessas já mencionadas, também se destacam aquelas em grandes lavouras de pêssego e soja ou atividades no comércio da cidade. Esses e outros elementos ajudaram a cristalizar as relações de patrão/empregado, em que o proprietário de terras controla trabalho e renda e, aliados à exclusão do acesso a direitos básicos, ao preconceito racial e ao êxodo rural, também influenciaram.

Diante desses efeitos da intensificação de uma agricultura voltada ao produtivismo, Shiva (1998) apresenta a crítica a um modelo de progresso com missão civilizatória atuante junto à lógica moderna de "desenvolvimento", que, baseado no critério do valor comercial, veria a diversidade do mundo biótico como transtorno. Configura-se, para Shiva, um amplo processo de opressões que conecta capitalismo e patriarcado, que se reforçam mutuamente e, para a autora, estão estreitamente ligados à perda em termos de biodiversidade. Podem se expressar como monopólios que realizam o controle de sementes, de comida e de mão de obra precarizada.

Nesse sentido, Maria Lugones (2014) propõe uma nova interpretação da modernidade capitalista colonial, que também inclui o debate sobre gênero. Para a autora, "a imposição colonial do gênero atravessa questões sobre ecologia, economia, governo, relaciona-se ao mundo espiritual e ao conhecimento, bem como cruza práticas cotidianas que tanto nos habituam a cuidar do mundo ou a destruí-lo" (Lugones, 2014: 935). A autora faz uma relação da ideia de colonialidade do poder, desenvolvida por Quijano (2005) ${ }^{12}$, com o debate sobre gênero. Lugones (2014) questiona um sistema binário de gênero que Quijano não problematiza e, para isso,

12 A partir de deslocamentos e problematizações das formas dominantes de compreender a modernidade e a colonialidade, os autores do chamado pensamento descolonial buscam encarnar um projeto intelectual crítico, a partir de deslocamentos e problematizações das formas dominantes de compreender a modernidade e a colonialidade, entendendo esse último como um processo para além do colonialismo enquanto experiência histórica, observando-a como um padrão de poder global por meio de hierarquizações étnicas, raciais e classe, e suas classificações derivativas de distinções como desenvolvimento e subdesenvolvimento e povos civilizados e primitivos. Ou seja, mesmo após o momento histórico da colonização, a colonialidade permanece como estrutura de pensamento que legitima as diferenças e hierarquias entre sociedades, sujeitos e conhecimentos (Quijano, 2005). 
menciona o "colonialismo de gênero", constituído pela imposição das opressões de gênero, racializadas e capitalistas, presentes na modernidade colonial. Para ela, uma lógica categorial que separa, porém hierarquiza categorias como se fossem homogêneas (tal como mulher ou negro) é um elemento central à modernidade.

Nas práticas cotidianas das mulheres, seguindo o pensamento de Lugones (2014), a resistência não pode deixar de ser evidenciada, mesmo em dimensões subjetivas. Teorizar sobre resistência nas imposições do colonialismo de gênero nos permite refletir não apenas sobre o posicionamento de oposição, mas também em formas de praticar a 'descolonização', seja nas práticas cotidianas ou formulações epistemológicas sobre as mulheres. A opressão não poderia e não teria espaço para ficar em um sentido estático, pois há formas de ação dessas mulheres que buscam romper com esses sistemas complexos de opressão. Maria Lugones (2014) aponta que, de modo criativo, há uma "proliferação relacional subjetiva/intersubjetiva da libertação, tanto adaptativa e criativamente opositiva. A resistência é a tensão entre a sujeitificação (a formação/informação do sujeito) e a subjetividade para que a relação opressão - resistência seja uma relação ativa, sem apelação ao sentido de agenciamento máximo do sujeito moderno" (Lugones, 2014:940). No entanto, mesmo que se fale em "existências colonizadas", a autora enfatiza que aquilo que daí emerge não é simplesmente fruto da ação hegemônica, dando espaço assim à agência dos sujeitos.

Os efeitos a longo prazo dessas relações patriarcais ligadas ao que o capitalismo expressa atualmente nas formas de constituição de novas maneiras de plantio e consumo influenciam nos modos de vida, como no caso da substituição de cultivos familiares por monocultivos, em uma tendência à uniformidade da produção e em tentativas de controle e homogeneização da natureza na tão propagada Revolução Verde e, mais recentemente, nas investidas da área da biotecnologia ${ }^{13}$. Separam-se, em muitos casos, processos de produção de consumo, intensificando uma economia produtivista já bastante questionada, porém ainda hegemônica e que também se relaciona a políticas de gênero, como define Vandana Shiva (1998).

Por outro lado, para a autora a diversidade aparece como um conhecimento especializado das mulheres do campo e suas tecnologias. Shiva (1998) faz críticas à falta de capacidade conceitual para definir o trabalho das mulheres do campo, pela própria diversidade dos trabalhos, que em maior quantidade, são concentrados fora do âmbito remunerado e formalizado. Consequentemente, isso gera a própria desvalorização dos trabalhos executados por mulheres. E essa invisibilidade do trabalho feminino também tem suas raízes do enfoque setorial, que fragmenta de forma reducionista, separando cultivos, o cuidado com os animais/gado e cultivos como independentes e não uma junção complementar.

Shiva também nos mostra a importância da guardiania de saberes e cultivares, como no caso das sementes, para as campesinas. Para a autora, ser guardiã demonstra a preocupação com a biodiversidade em escala mundial e, como o caso

13 A fala de Shiva está localizada nas zonas rurais da Índia, onde as mulheres desempenham práticas e lógicas de produção que permitiram sua reprodução social a partir de conhecimentos específicos. 
por ela apontado, das zonas rurais da Índia, onde a conservação da biodiversidade local aparece como categoria conservacionista, com uma específica significação para aquilo que é considerado por elas sagrado. Sementes modificadas geneticamente seriam profanas (envenenadas), dado que a integridade do ciclo e o nexo ecológico de todo englobamento teria sido interrompida. Tal nexo significa uma relação imbricada entre diferentes fatores, por exemplo, uma combinação de sementes de cereais mantém o equilíbrio com o ciclo do nitrogênio.

Além disso, a diversidade de sementes auxilia na manutenção da fertilidade do solo e há uma relação afetiva com as sementes: "las semillas que cultivan las hijas". Para além de aspectos agrícolas, os monocultivos dificultam a subsistência, aumentando a dependência dos produtores e produtoras, distanciando produtores e consumidores/as em um mercado cada vez mais global. Shiva propõe pensar a biodiversidade como um conjunto que não se encontra no valor econômico e sim no valor de uso. O controle da biodiversidade do chamado sul global não é algo novo, nota-se que Shiva (1998) estava escrevendo em 1998, época em que o debate sobre sementes geneticamente modificadas (transgênicas) estava em ápice, expostas como "salvação" para a fome nos países do terceiro mundo. Mas, ao mesmo tempo, este sul global, muitas vezes chamado de "terceiro mundo" ou "subdesenvolvido", é colocado como "pobre" diante de fortes interesses corporativistas e sua importância na conservação da riqueza biológica é frequentemente minimizada.

Se para as mulheres campesinas, afirma Shiva (1998), o valor essencial das sementes reside na continuidade da vida, é interessante pensar que para empresas de biotecnologia, a criação e o patenteamento de sementes que não possibilitam futuras gerações (e precisam ser compradas a cada safra, como no caso da soja) levam ao seu oposto, a descontinuidade da vida, potencializada pelo fato de se restringir às grandes propriedades. Assim, agricultoras e agricultores deixam de ser guardiões para tornarem-se consumidores. A semente entra na lógica de propriedade privada, como não somente a variação genética e sim uma criação da empresa que a "detém", com a ajuda de instituições de pesquisa, poder público e organizações privadas.

Assim, se é no complexo de imposições de tecnologias ocidentais ao campo que se nota a depreciação de atividades realizadas pelas mulheres e o não reconhecimento das múltiplas formas de conhecimento que advêm de suas mãos, dentre a multiplicidade de funções, frentes de atuação e tarefas desempenhadas, cabe mencionar que, apesar de seu peso e influência estes processos não levam a um apagamento de diferentes expressões da produção e dos meios de subsistência ou a um local simplesmente de ausências.

Saindo da produção agropecuária e entrando nas cozinhas, com um misto de nostalgia e sentimento de superação, são lembrados pelas mulheres quilombolas bolos ou pães de pedra (assados em uma pedra chata aquecida na brasa), com torresmo de gado ou não, diversos alimentos derivados do milho (bolos, bolachas, polenta, cuscuz, canjicas etc.), broas, bolachas, a sopa de leite, bolos salgados de torresmo de porco, entre muitos outros, transmitidos entre as gerações pelas mulheres, descritos em Pinheiro e Rodrigues (2015). Entre continuidades e inovações, 
alguns desses alimentos seguem sendo plantados e consumidos, outros foram substituídos por industrializados, a partir de critérios que se renovam. O milho, por exemplo, atualmente, ora é associado ao estigma da privação, ora é valorizado na base alimentar cotidiana (Pinheiro e Rodrigues, 2015). Entremeados com as receitas culinárias, surgem temas profundos, como violência doméstica, fome, preconceito racial, mas também a superação das dificuldades. No que é rememorado como tempo antigo, emergem relatos de comida escassa, de trabalhos precários, de distância da medicina e de tratamentos convencionais, mas também o desenvolvimento de refinados conhecimentos sobre a alimentação e sobre a cura com ervas de chá e orações.

A reafirmação do território, da relação de pertencimento das pessoas com um lugar e seus modos de vida, bem como, por outro lado, as renovações das dinâmicas externas, podem ser vistas a partir de uma dimensão mais ampla, relacionando as diferentes expressões de identidades negras. Há uma potência da conexão entre o território e o pertencimento em comum, com a articulação de uma memória e um destino partilhado entre lugares, grupos e indivíduos, que podem se modificar ao longo do tempo. A Associação Quilombola do Rincão das Almas, formada em 2006, majoritariamente com mulheres à sua frente, permanece como uma possibilidade de mobilização, tendo o parentesco não somente como um modo de organização das relações pessoais, mas também como parte do sistema de relações políticas. Ações iniciais de assistência técnica via projetos de desenvolvimento foram realizadas a partir do final dos anos 1990, muitas das quais fazem parte de uma agenda mais geral voltada ao espaço rural, mas que não eram acessadas pelos quilombolas (cf Pinheiro, 2015). Em muitas destas ações ${ }^{14}$, estimuladas ou mediadas pelo poder público, estão implícitos objetivos civilizadores, mesmo que revestidos de discursos de valorização cultural, mas as intervenções externas não possuem as credenciais e garantias para uma autoridade sem questionamentos, portanto as negociações e adaptações são constantes e há significativa adesão local nessas iniciativas.

De todo modo, com essas ações, há algumas mudanças em relação às condições de precarização do trabalho, o acesso a direitos e a desvalorização de saberes alimentares e de cura guardados por mulheres quilombolas. Não é mais necessário se submeter a condições extremas ou trocar trabalho por comida, utensílios ou animais para a produção, porque os projetos de intervenção parcialmente supririam essas necessidades materiais para a retomada da produção, mesmo que em pequena escala. Alia-se a isso o processo de implementação efetiva de benefícios sociais, como aposentadorias e programas sociais - muitos dos quais voltados às mulheres, pelo seu protagonismo na soberania alimentar -, que teve como resultado uma menor dependência dos quilombolas em relação aos antigos patrões, modificando relações de poder locais, como também relata Dutra (2011) em levantamento sobre os quilombos de toda a região.

14 Que incluem desde programas de habitação, assistência técnica para produção agropecuária, artesanato até cursos de alimentação saudável e uso de plantas medicinais. 
Diante da atual ofensiva a direitos sociais que se agravou no ano de 2016 no Brasil, além das dificuldades já mencionadas, da falta de terra para o plantio e para a criação de animais e limitações em termos de acesso e guardiania de sementes, outro fator que tem pesado é justamente a falta de continuidade nas iniciativas mencionadas acima. Assim, se foram possíveis algumas melhorias nas condições de acesso a direitos, no entanto, também ocorreram inúmeros percalços, e a cidadania, nesse caso, parece ser sempre incompleta e instável. A posição de sujeito de direitos, com isso, mostra limites sobre quais direitos está se falando, de que maneira eles poderiam ser materializados e a que custo as ações acabam sendo efetivadas.

\section{Saberes como patrimônio}

É importante situar as formas de organização que as mulheres aqui mencionadas buscaram para reivindicar os sentidos de seus conhecimentos e práticas, criando epistemologias que questionam noções ecológicas, econômicas e culturais, reflexões que Vandana Shiva, Lorena Cabnal e Maria Lugones trazem para pensar esses intercâmbios de ideias em alguma medida partilhadas por mulheres de diferentes partes do globo. A formulação de novas epistemologias que partem de ou para lutas locais também é importante para pensar formas de descolonização. Bahri (2004) indica que para entender as perspectivas feministas fora da relação "Mulheres do Primeiro Mundo falando sobre Mulheres do Terceiro Mundo”, precisaríamos aprender a ler representações literárias de mulheres levando em conta tanto o sujeito quanto o meio de representação, ou seja, o local.

Consideramos aqui que há experiências de vida singulares, com base em contextos históricos, que influenciam modos de ver e estar no mundo, que não permitem falar em uma única forma de opressão nem de experiências; as matrizes de subordinação não são homogêneas nem só vinculadas a um patriarcado ocidental. Ao trazer as condições históricas e sociais de mulheres negras e assentadas da reforma agrária, perpassadas de modo heterogêneo pelo racismo, sexismo e/ou colonialismo, chamamos a atenção para o reconhecimento de experiências singulares marcadas por sistemas classificatórios que prejudicam o seu protagonismo e complexificam a diferença.

Ao intercalar a discussão sobre terra e corpo na constituição de práticas e saberes formulados por mulheres, percebemos que as mulheres mencionadas possuem uma noção de bem-estar que conecta territórios - tanto o corpo quanto a terra - e os faz coletivos, partilhados. Colheitas são compartilhadas, retribuídas por bolos e alimentos distribuídos entre familiares, ou ainda, cuidados e remédios oriundos do cultivo de plantas são multiplicados e reforçam a importância do trabalho coletivo das assentadas nas farmacinhas.

Em seus territórios, passaram por tentativas de exploração pelo agronegócio, em suas investidas de modernização no campo, pelo Estado em políticas públicas 
pouco participativas, por inúmeras situações de conflito na luta pela terra ou pelas injustiças da expropriação fundiária. Passaram também por discriminação e racismo, e mesmo a violência em situações domésticas, muitas vezes não relatadas. Tratam-se de violências sobre aquilo que constitui a condição de vida, e uma série de desafios em torno do manejo e extração de valiosos bens naturais que têm se desenvolvido com vigor em múltiplos locais ironicamente considerados "pobres". E mesmo que seja senso comum um desenvolvimento baseado no discurso de "melhorar a vida dos povos", criando estratégias de participação e envolvimento das comunidades no trabalho de exploração econômica, o domínio permanece sendo o da lógica do monopólio econômico.

Por meio de práticas de cuidado entre si e com a terra, estas mulheres defendem sua liberação, mantendo a prática de cura, produção e alimentação a partir de conhecimentos adquiridos na experimentação, conservando participativamente a biodiversidade e como guardiãs de saberes e práticas associadas. Por isso a necessidade de uma prática transgressora, criadora e transformadora - mesmo que nem sempre isso se dê de modo explícito. Assim, as práticas e memórias sobre cura e alimentação são também referências que influenciam ações coletivas e fortalecem os territórios (terra e corpo). E o que anteriormente era somente símbolo de "atraso", atualmente pode ser ressignificado sob outra perspectiva, como patrimônio cultural. Assim, permanece a reivindicação de direitos básicos voltados ao respeito aos territórios e modos de vida, que permita a reprodução criativa de práticas e saberes sobre o plantio e consumo dos alimentos e as práticas de cura. Ou seja, não falamos somente em sobrevivência, mas sim de experiências, processos criativos e vivências, de modo ativo.

Por fim, não buscamos aproximar estes elementos da vida cotidiana com o corpo de conhecimento teórico que se vê e vê ao Outro como parte de uma grande narrativa civilizacional, como aponta o debate presente em Rosa (2014), e sim buscar em perspectivas não hegemônicas aportes teóricos para refletir sobre a temática proposta, de modo a não excluir as epistemologias feministas do pensamento social, como também reforça Oyěwùmí (2004).

\section{Referências}

BAHRI, D. (2004). Feminims and/in Postcolonialism. In: LAZARUS, Neil (Ed.). The Cambridge Companion to Postcolonial Literary Studies. Cambridge: Cambridge University Press, 2004. p. 199-220.

CABNAL, L. (2010) Acercamiento a la construcción de la propuesta de pensamiento epistémico de las mujeres indígenas feministas comunitarias de Abya Yala. In: Feminismos diversos: el feminismo comunitario, Madrid: Acsur Las Segovias, pp. 11-25. 
CASTRO-GÓMEZ, S. (2005). La Poscolonialidad explicada a los niños. Cauca: Universidad del Cauca/Instituto Pensar - Universidad Javeriana.

DE CARLI, A. (2013). A arte de narrar a vida: um estudo etnográfico de duas famílias assentadasdo Rio GrandedoSul.2013.115p. Dissertação (Mestradoem Desenvolvimento Rural). Universidade Federal do Rio Grande do Sul, Porto Alegre, RS.

DUTRA, M. V. F. (2011). Direitos Quilombolas: um estudo do impacto da cooperação ecumênica. Rio de Janeiro: Koinonia.

FEDERICI, S. (2010). Calibán y la Bruja. Mujeres, cuerpo y acumulación originaria. Buenos Aires: Tinta Limón Ediciones.

LEITE, I. B. (2000). Os quilombos no Brasil: questões conceituais e normativas. Etnográfica, Lisboa, v. 4, n. 2, p. 333-354.

LUGONES, M. (2011). Rumo a um feminismo descolonial. Estudos Feministas, Florianópolis, 22(3): 320, setembro-dezembro/2014.

MARQUES, F.C. (2008). Biodiversidad y Salud: casos de trabajos comunitarios de mujeres agricultoras en la Región Sur de Brasil. VIII Congreso Científico de Sociedad Española de agricultura ecológica. Disponible en: < http://www.agroecologia. net>Acceso el 14 oct. 2014

MOLL, S. (2010). Las Trementinaires del Valle de la Vansa y Tuixén: Saberes femininos en la cuerda floja.

OYĚWÙMÍ, Oyèrónké. Conceptualizing Gender: The Eurocentric Foundations of Feminist Concepts and the challenge of African Epistemologies. African Gender Scholarship: Concepts, Methodologies and Paradigms. CODESRIA Gender Series. Volume 1, Dakar, CODESRIA, 2004, p. 1-8.

PINHEIRO, P. S. (2015). Políticas de Identificação: Dinâmicas de reconhecimento identitário de comunidades negras rurais no sul do Brasil em um contexto de relações interétnicas. 2015. 226 p. Tese (Doutorado em Ciências Sociais em Desenvolvimento, Sociedade e Agricultura). Universidade Federal Rural do Rio de Janeiro, Rio de Janeiro, RJ.

PINHEIRO, P.; RODRIGUES, C. V. Entre memórias e ressignificações de práticas alimentares: um estudo sobre alimentação em comunidades negras rurais. In: Menasche, Renata (Org.). Saberes e sabores da colônia. Porto Alegre: Ed. UFRGS, 2015.

PRECIADO, B. (2008). Testo Yonqui. Madrid: Editorial Espasa. 
QUIJANO, A. (2005). Colonialidade do poder, eurocentrismo e América Latina. In: Lander, E. (org). A colonialidade do saber: eurocentrismo e ciências sociais. Perspectivas latino-americanas. Colección Sur Sur, CLACSO, Ciudad Autónoma de Buenos Aires, Argentina. pp.227-278. Disponível em <http://bibliotecavirtual.clacso. org.ar/ar/libros/lander/pt/Quijano.rtf>

RICH, A. (1985). Heterosexualidad obligatoria y existencia lesbiana. In: Nosotras que nos queremos tanto. Madrid, n.3, p.5-35.

RODRÍGUEZ, M. P. C. (2017). Tejiendo Prácticas En Una Farmacinha Casera Del MST: Memorias de mujeres del assentamento 12 de julho (Canguçu/RS) sobre el uso de plantas medicinales. Dissertação (Mestrado em Memória e Patrimônio). Universidade Federal de Pelotas.

SHIVA, V. (1998). El saber proprio de las mujeres y la conservacion de la biodiversidad. In.: Mies, Maria; SHIVA, Vandana. La Praxis Del Ecofeminismo: Biotecnología, consumo, reproducción. Barcelona: Icaria,

ROSA, M. (2014). Sociologias do Sul. Civitas, Porto Alegre, v. 14, n. 1, p. 43-65, jan.-abr. 